\title{
Transiciones democráticas en América Central: $1979-1995$
}

\author{
Joan Botella \\ Universitat Autonoma de Barcelona. Departament de Sociologia. \\ 08193 Bellacerra (Barcelona). Spain
}

\section{Resumen}

La naturaleza de las transiciones democráticas en Centroamérica desde 1979 (en sus éxitos y en sus fracasos) requiere modelos más complejos para el análisis del cambio político. La discusión tradicional sobre los pre-requisitos de las dernocracias debe acompañarse con un análisis preciso de las estrategias de los actores politicos. Además, la ausencia de una divisoria precisa entre transición y consolidación democrática hace que su capacidad para cofrentarse a los problemas sociales y económicos (especialmente en sociedades en que esos problemas, en términos de upre-requisitos", resultan problemáticos) sea críticamente importante para el propio proceso de transición: su rendimiento (en términos de establecimiento de la agenda y de eficacia) es una condición del éxito de las transiciones.

Se sugiere un esquema simple, integrando esos tres tipos de variables.

Palabras clave: transiciones democráticas, gobernabilidad, América Central.

Abstract. Democratic transitions in Central America: 1979-1995

The nature of democratic transitions in Central America from 1979 onwards (and both their successes and failures) calls for more complex and large analyrical models for the analysis of political change. The traditional discussion about the pre-requisites of democracy has to be accompanied by a thorough discussion of the nature and strategies followed by political actors. Finally, given the absence of a clear-cut separation berween democratic transition and consolidation of the new democracies, their ability to cope with social and economic problems (especially in those countries where these issues, in terms of pre-requisites, are scarcely promising) becomes critically important for the ransition process itself: their performance (in terms of agenda definition and efficiency) is clearly a condition for the success of transitions.

A simple framcwork, integrating these three types of variables, is suggcsted.

Key words: democratic cransitions, governability, Central America. 
En un texto fechado en 1979, un relevante politólogo latinoamericano, Enrique Baloyra, detectaba solamente dos transicioncs democráticas recientes en el continente americano: los procesos de cambio en la República Dominicana (1978) y en Ecuador (1979). A la luz de los recientes, en aquel momento, procesos de transición vividos en Grecia, Portugal y España, el propio autor se preguntaba si no sería posible que las dictaduras latinoamericanas entrasen en una vía similar. En cualquier caso, las dictaduras correspondientes, en sus propias palabras, a "regímenes tradicionales" eran las que ofrecían perspectivas más oscuras ante la posibilidad de una eventual transición democrática. Y en este grupo se incluían El Salvador, Guatemala y Honduras; mientras Nicaragua sc encuadraba, ya en aquel momento, en el grupo de países "en vías de transición»"

Con la perspectiva del tiempo, y tras haber vivido los enormes procesos de cambio político que América Latina ha conocido desde entonces, sería injusto confrontar la hipótesis de Baloyra con las realidades actuales. Y, sin embargo, sigue siendo cierto que los países del istmo ofrecen un panorama distinto, y menos luminoso, que la gran mayoría de América Latina ${ }^{2}$. Mientras las dictaduras, tanto de tipo tradicional como de tipo "neoautoritario", han sido derrotadas en la cuasi totalidad del continente, dando lugar a regímenes democráticos, más o menos consolidados, pero que en todo caso muestran una capacidad de resistencia mayor que anteriores experiencias democráticas, los países de América Central ofrecen una panorámica distinta.

Los estudios recogidos en este volumen de PAPERS ofrecen aproximaciones diversificadas a las distintas dimensiones (nacionales o temáticas) de esta problemática global. En todo caso, una primera reflexión se impone: de modo semejante a la distinción entre "democracias fáciles" y "democracias dificiles" propuesta hace tiempo por Sani y Sartori (Sani, Sartori 1978), ¿cabe hablar de transiciones fáciles o dificiles? ¿ Qué condiciones, en su caso, permiten o dificultan que los procesos de transición democrática tengan una mayor o menor viabilidad?

Más en concreto: podemos plantearnos el problema en tres ámbitos claramente distintos. Por una parte, cabe plantearse qué contextos sociales hacen más viable (o, por contra, más difícil) el paso de una situación autoritaria a una democracia. El discurso sobre los prerrequisitos sociales y económicos de las democracias es uno de los más tradicionales, que podemos remitir a los trabajos iniciales de Lipset o Rustow.

Una segunda dimensión, explorada más recientemente (pero con una literatura ya inmensa), es la de las características del proceso de transición. Aquí la atención de los investigadores se ha concentrado csencialmente en los actores de los procesos de transición, identificando sus estrategias, la lógica de su interacción, etc. Mientras en el primer ámbito se privilegiaba la comprensión del

1. Ver Baloyra (1981), especialmente p. 303-311 y p. 318.

2. Por América Central nos referimos, en el contexto del proyecto de investigación, a los paises continentales al sur del Canal. Ello excluye los casos de México y Panamá, asi como la rica realidad caribeña. 
impacto político de factores de tipo socioestructural, en esta problemática la atención se concentra en el plano estrictamente político.

La tercera dimensión (y también la de construcción teórica y analítica más reciente) tiende a preocuparse por los rendimientos del nuevo sistema polírico democrático. Dada la centralidad de la cuestión de la legitimidad para un sistema democrático, y dado el hecho de que tras una transición democrática todo sistema político es "nuevo" (rompiéndose pues con la lógica de legitimidad del anterior sistema), la capacidad del nuevo sistema para responder a las demandas y expectativas sociales es un elemento crítico para su legitimación. Puesto que, en definitiva, las sociedades no sólo esperan que sus sistemas politicos sean democráticos, sino que puedan enfrentarse eficazmente a la resolución de algunos problemas sociales, esta dimensión adquiere una relevancia central.

Sería tentador, por una parte, revisar la literatura sobre las transiciones democráticas en base al énfasis puesto en cada una de estas tres dimensiones. En segundo lugar, y de modo muy esquemático, se podría observar que el ya extenso conjunto de casos registrados en los últimos veinte años podría subdividirse internamente atendiendo al peso relativo de las mencionadas variables en el seno de cada proceso. Así, de modo intuitivo, cabria sospechar que el razonamiento en términos de prerrequisitos puede ser relevante para comprender los casos de América Central ( $\mathrm{y}$ los mucho menos estudiados del África negra); el razonamiento en términos estrictamente políticos podría tener una mayor operatividad en los casos "europeos»; y que la dimensión "rendimiento" sería de crítica importancia para comprender los casos de la Europa central y oriental.

Sin embargo, un esquema de este estilo sería excesivamente simple y mecánico. De hecho, toda transición se produce en una cierta sociedad, cuyos rasgos estructurales pueden facilitar o dificultar el proceso; en segundo lugar, el camino de la transición es siempre político, aunque el protagonismo pueda no estar monopolizado por fuerzas políticas (por ejemplo, fuerzas armadas, actores sindicales, movimientos sociales, etc.). Finalmente, todo nuevo sistema político debe preocuparse por conquistar la legitimación ante sus súbditos en base a los modos y contenidos de su acción de gobierno (nada nuevo, en definitiva: ya Maquiavelo había escrito páginas ejemplares acerca de qué debía hacer un "príncipe nuevo" para afirmar su dominio).

Por consiguiente, necesitamos un modelo integrado, que atienda a los tres tipos de dimensiones enunciadas, y que permita a la vez comprender la lógica de los procesos reales y, al mismo tiempo, pueda detectar los casos "críticos", los procesos desviantes. Por tanto, es preciso disponer de un instrumento de análisis más complejo que la simple distinción entre "transición" y "consolidación" democráticas, la atención a la pervivencia política o no de los exponentes del antiguo régimen, o a la fidelidad o no de los nuevos gobernantes democráticos respecto de su programa político tradicional, ctc.

La cuestión, más bien, debe dirigirse a detectar las variables, o conjuntos de variables, relevantes para comprender en qué condiciones las tres dimensiones cnunciadas posibilitan un proceso de transición "fácil» y una consoli- 
dación democrática amplia y rápida. Esta operación es la más compleja posible, puesto que el proceso de definición de estas variables no puede basarse en un razonamiento de tipo ex post facto, dado que entonces estaríamos limitándonos a describir en términos generales un caso concreto, o varios.

Sobre la base de la literatura sobre las transiciones democráticas, de los estudios aquí recogidos (y más, en general, de la experiencia investigadora conjunta del grupo), cabe atreverse a especificar algunas de estas variables. (Una útil síntesis, aunque anterior a los procesos en la Europa central y oriental, está constituida por el trabajo de Huntington, 1991.)

Por lo que respecta a la dimensión societal, dos tipos de variables parecen tener un papel clave. Aceptamos, en primer lugar, la relevancia atribuida al desarrollo económico y social por los clásicos de la literatura sobre los "prerrequisitos" de la democracia, que, sin embargo, ya no cabe interpretar ni en términos de condición suficiente ni de requisito necesario (quedan algunas dictaduras "affluent", mientras existen democracias "pobres").

Pero junto a este dato, un segundo elemento ha venido adquiriendo un papel central: el grado de integración social-nacional. La existencia de comunidades segregadas (sobre bases étnicas, linguísticas, culturales ut otras) constituye un elemento que la experiencia reciente (destacadamente en Europa central y oriental, pero también en nuestros contextos de América Central) sugiere que no puede ser menospreciado.

Las variables estrictamente politicas que caracterizan al proceso son posiblemente más fáciles de operacionalizar. Parece claro un consenso en la literatura acerca del papel clave de la propensión a la negociación de las diversas elites políticas implicadas, tanto en el seno del sistema autoritario como entre la propia oposición democrática; pero no hay que pasar por alto la importancia capital de la inclusividad del proceso: dada la probable división interna de las fuerzas "tradicionales" como la inevitable fragmentación de las fuerzas democráticas, una negociación sólo puede ser significativa en la medida en que lo sea la pluralidad y la representatividad de los actores implicados. Debemos ir más allá, en consecuencia, de las tipologías de "herederos", "challengers", etc.

Finalmente, la dimension "rendimiento" puede ser también estructurada internamente en un doble ámbito. Ya hemos mencionado el papel esencial de la percepción de la eficacia de la acción de los nuevos gobernantes democráticos. Pero, a la vez, la eficacia se refiere sólo a la relación entre objetivos propuestos y resultados objetivamente alcanzados. Ahora bien, la propia definicion de objetivos, la configuración de la agenda es en sí misma un elemento capital para la legitimación del sistema democrático: esta sexá mayor si un número mayor de colectivos sociales sienten sus objetivos atendidos por los gobernantes, con relativa independencia de la eficacia en su gestión. En definitiva, la inclusión en La agenda es de por sí relevante.

Nos parece particularmente importante subrayar este último aspecto, para evitar los problemas planteados por la habitual distinción entre transición democrática y consolidación del nuevo sistema democrático. En particular, esta distinción sugiere un encadenamiento lineal entre ambos procesos: tras la transición 
(etapa más o menos breve) se inicia la consolidación, cuyos indicadores son definidos de modo variable por los diversos autores, pero frecuentemente apuntando a un plazo medio o largo (por ejemplo, insistiendo en la significación de los cambios en las culturas políticas\}.

En los últimos años, el desarrollo del interés por las reformas económicas y por las políticas sociales emprendidas por los nuevos sistemas democráticos ha configurado una interesante área, de ciclo cronológico intermedio, que puede constituir una aproximación más operativa a los procesos inmediatamente postransición. En todo caso, esta problemática puede ser útil para comprender los procesos de transiciones "inestables", que conducen con frecuencia a retornos autoritarios, a situaciones precarias o a salidas de tipo no democrático, situaciones todas ellas visibles en nuestro contexto de América Central. (Véase, por ejemplo, el reciente estudio de Maravall 1995; o el de Bresser, Maravall, Przeworski, 1995.)

Asf, podemos construir un esquema general, especificando las variables relevantes para configurar cada una de las tres dimensiones enunciadas; podemos dar un paso más, si efectuamos algún tipo de medición de cada una de esas variables. Naturalmente, su nivel de abstracción impide una medición cuantitativa; pero podemos distinguir, al menos, y sobre la base de informaciones generales, entre valores "al tos" y "bajos".

Sobre esta base podemos construir un esquema como el que incliye la tabla 1. Este esquema, naturalmente, es sólo orientador: su aplicación a casos concretos requeriría una definición más precisa de los correspondientes indicadores. En todo caso, un elemento aparece con claridad a la vista de una presentación de este estilo: todas las dimensiones consideradas ofrecen, para los casos de América Central, unos valores muy bajos. Ello es bien conocido por lo que respecta a los niveles de desarrollo socioeconómico. Pero a la vez el grado de integración nacional de aquellas sociedades es igualmente bajo: la contraposición entre campo y ciudad, la marginación de muy amplias comunidades indígenas o la existencia de comunidades culturalmente diferenciadas son datos bien conocidos.

Tabla 1. Transiciones fáciles y dificiles: tres dimensiones de variables explicativas.

\begin{tabular}{lll}
\hline Dimensión & Variables relevantes & Valores \\
\hline $\begin{array}{l}\text { Prerrequisitos } \\
\text { socioeconómicos }\end{array}$ & - Nivel de desarrolto & Altos (A) \\
& economico & Medios (M) \\
Proceso político & - Integración nacional & Bajos (B) \\
& - Propensión negociadora & Altos (A) \\
& - Inclusividad & Medios (M) \\
Rendimiento de & - Elaboración de la agenda & Bajos (B) \\
las políticas & - Eficacia $(\mathrm{A})$ \\
& & Medios (M) \\
& & Bajos (B) \\
\hline
\end{tabular}


Por lo que se refiere, a las características del proceso, el diagnóstico es igualmente claro. La dificulrad en construir sistemas de partidos medianamente reconocibles y estables a lo largo de los últimos quince años, ha dificultado cnormemente el desarrollo continuado de procesos de transición democrática. El predominio de una lógica militar, tanto de tipo conservador como de tipo insurreccional, o la frecuente formación de coaliciones "negativas", enormemente heterogéneas en términos políticos e ideológicos (recuérdese, por ejemplo, el caso de UNO en Nicaragua), han dificultado la emergencia de actores políticos claros, representativos de grupos sociales, en condiciones de agregar y representar de modo adecuado sus intereses.

Finalmente, las reformas económicas se han puesto en marcha, frecuentemente, incluso antes del lanzamiento de procesos democratizadores, interfiriendo en su lógica y subordinando la mecánica de la transición a la acción de intereses exteriores y a los impactos diferenciados de aquellas reformas sobre un tejido social ya de por si precario.

Los estudios incluidos en este trabajo no abarcan el conjunto de las tres dimensiones indicadas, sino que se concentran en el análisis de los procesos de cambio (mientras las investigaciones en curso se están dirigiendo a la exploración del tercer plano: la construcción de la agenda y la capacidad de gobierno eficaz de los nuevos gobiernos). Abrimos con el estudio de Torres Rivas, que plantea el marco global de la cuestión de la gobernabilidad de las sociedades centroamericanas en los contextos de transiciones difíciles que las han caracterizado. La centralidad corresponde, no sólo a las transformaciones políticas, sino también al crecimiento economico y a la lucha contra la pobreza, como elementos definitorios de la propia naturaleza de los procesos de transición. Naturalmente, esta línea de análisis debe proseguirse y desarrollarse, y es en esta dirección en que se mueven los actuales trabajos en curso.

Con mucho, el grueso de nuestra atención se ha dedicado a la formación y a las características de los actores políticos. Los estudios de Sojo, Alcántara, Gomà y Font, y Cardenal y Marrí, adoptan un planteamiento comparativo. Mientras Sojo y Alcántara, en un plano teórico, examinan la situación de los partidos de corte "tradicional" y su interacción con los actores políticos de reciente "fundacion", los otros dos estudios se centran más bien en los actores sociales y en la caracterización de las "arenas" políticas.

Las transformaciones institucionales son un elemento clave en este terreno. Los estudios de Gerpe y Vintró (sobre las reformas constitucionales) y de Vilas (sobre la aplicación de los acuerdos pacificadores en El Salvador) plantean la pregunta de hasta qué punto, en la ausencia de "legitimación recíproca" entre "herederos" y "democratizadores", los elementos institucionales, por sí solos, no estabilizan suficientemente los procesos y, por el contrario, tienden a transformarse en instrumentos de disenso antes que en forjadores de actuerdos estables.

En conjunto, el lector tiene entre sus manos una colección de estudios para los que las variables relativas a la dimensión societal (o, en otros términos, los prerrequisitos de las democracias) tienen una dimensión muy homogénea. 
Con todas las diferencias que se puedan observar, los países del istmo comparten niveles de desarrollo económico y social bajos, y (en algunos casos) problemas serios de baja integración nacional. Por consiguiente, constituyen un buen «laboratorio" para examinar la dinámica de las variables estrictamente políticas. Más en concreto, con relación a los actores de los procesos de transición y a las características de dichos procesos.

De rebote, estos estudios permiten hacerse algunas preguntas sobre "el caso" tenido por ejemplar en los estudios sobre las transiciones democráticas: el caso español. Su supuesto carácter "ejemplar" queda enormemente redimensionado tras el análisis de otros procesos de transición. En realidad, el caso español parece ser un caso completamente excepcional, en el que todas las variables significativas condicionadoras cobraban valores altos. La suavidad del proceso español y su éxito relativamente rápido y poco costoso tienen que ver con unas condiciones excepcionales, claramente desviantes respecto de las que han caracterizado otros contextos.

\section{Bibliografía}

BALOXRA, Enrique A. (1981): "La transición del autoritarismo a la democtacia en el sur de Europa y en América Latina: Problemas teóricos y bases de comparación". En SANTAMARłA, Julián (compilador), Transición a la democracia en el sur de Europa y América Latina. Madrid: CIS, p. 287-345.

Bresser Pereira, L.C.; MARAVall, J.M.; PrZeworski, A. (1995). Las reformas economicas en las nuevas democracias. Un enfoque socialdemócrata. Madrid: Alianza Ed.

HUNTINGTON, S.P. (1991). The Third Wave. Democratization in the late Twentieth Century. Norman, Londres: University of Okjahoma Press.

Maravall, J.M. (I995). Los resultados de la democracia. Madrid: Alianza Ed.

SANI, G.; SARTORI, G.(1978), «Frammentazione, polarizzazione e cleavages: Democrazie facili e difficilim. Rivista Italiana di Scienza Politica, núm. 3, p. 339-361. 